Article

\title{
An Application of the Walkability Index for Elderly Health-WIEH. The Case of the UNESCO Historic Centre of Porto, Portugal
}

\author{
Fernando Alves ${ }^{1, *}$, Sara Cruz ${ }^{1, * \mathbb{D}}$, Sophia Rother $^{2}$ and Tino Strunk ${ }^{2}$ \\ 1 Research Centre for the Territory, Transports and Environment, Faculty of Engineering, University of Porto, \\ 4200-465 Porto, Portugal \\ 2 Fachhochschule Erfurt, 99085 Erfurt, Germany; up202002517@fe.up.pt (S.R.); up202002689@fe.up.pt (T.S.) \\ * Correspondence: alves@fe.up.pt (F.A.); scruz@fe.up.pt (S.C.); Tel.: +351-911743737 (F.A.)
}

Citation: Alves, F.; Cruz, S.; Rother, S.; Strunk, T. An Application of the Walkability Index for Elderly Health-WIEH. The Case of the UNESCO Historic Centre of Porto, Portugal. Sustainability 2021, 13, 4869. https://doi.org/10.3390/su13094869

Academic Editor: José

Carmelo Adsuar

Received: 30 March 2021

Accepted: 22 April 2021

Published: 26 April 2021

Publisher's Note: MDPI stays neutral with regard to jurisdictional claims in published maps and institutional affiliations.

Copyright: (c) 2021 by the authors. Licensee MDPI, Basel, Switzerland. This article is an open access article distributed under the terms and conditions of the Creative Commons Attribution (CC BY) license (https:// creativecommons.org/licenses/by/ $4.0 /)$.
Abstract: This work provides a follow-up to the article Walkability Index for Elderly Health: A Proposal, published in 2020. Previous research linked the quality of public spaces, walkability characteristics relevant to older people, and the direct health benefits of walking for the same target group. The present article, on the other hand, aims to validate the conceptual design of the walkability index for elderly health (WIEH), developed by the authors in the previous study, by applying it to a study area located in the historic center of Porto, Portugal. Therefore, public spaces and the pedestrian network are analyzed according to their suitability for older people's walkability. Presented in a visual format, the results show that only a few paths within the study area were strongly suited to older people, and emphasize the impact of existing steep slopes on the quality of the pedestrian network.

Keywords: older people's health; age-friendly spaces; public space quality; walkability index; Porto historic center

\section{Introduction}

Walking is widely considered one of the most important forms of locomotion for older people, due to its direct and beneficial health effects [1]. Interventions to improve older adults' walking practices have historically been multifactorial and, for the most part, undertaken within the field of gerontology and geriatric medicine, and thus focused mostly on improving underlying impairments [2].

There are various separate studies on the quality of public spaces, older people's walkability characteristics, and the health benefits of walking for older people [3-12]. The article Walkability Index for Elderly Health: A Proposal [13], published in 2020, offers a methodological approach to link these three topics. This methodology was developed by the authors in the previous study. Based on a literature review, in this previous article we researched the conceptual design of a walkability index for improving the health of older people, which could be used to map the most adequate, age-friendly, and healthy routes for older people, in any city.

In this follow-up study, the Walkability Index for Elderly Health (WIEH) is applied to a study area partly within the historic center of Porto. The aim of this work was to validate the conceptual design of the index by testing it on a real urban space, as per the two initial steps for index application determined by the previous research work: (1) analyzing public spaces and classifying their quality for walking, and (2) considering the presence of slopes and stairs. The medieval structure of the study area was taken into account in the application and evaluation of the index.

In the study area, the pedestrian network was thus categorized, in this study, into four categories: most age-friendly, reasonably age-friendly, less age-friendly, and not agefriendly. Backed by the results obtained during this empirical research phase, a proposal 
on how to improve the case study's pedestrian network for older people is presented, as well as some recommendations regarding the index application process.

\section{Older People's Pedestrian Mobility in the Historic Centers}

Walking is one of the most important methods of locomotion for older people, as it allows them to move individually. The primary reasons that motivate walking include shopping, health care issues, and recreational purposes [14] —in short, access to basic and secondary services, usually at an average distance of $400 \mathrm{~m}$ to $800 \mathrm{~m}$ from the starting point $[4,15]$. The importance of walking as a mode of transport is increasingly being emphasized, as walking on a regular basis can improve the health of older people and prevent chronic illness. The latest guidelines of the World Health Organization [16] recommend that, in order to remain healthy and fit, older people should walk at least 150-300 min per week at a moderate pace, or 75-150 min per week with vigorous intensity, in accordance with their individual capacity. Several National Health Organizations provide guidelines for physical activity similar to the recommendations of the $\mathrm{WHO}$, informing and encouraging older people to walk on a regular basis [17-19].

A study by Notthoff and Carstensen [20] demonstrated that motivational messages about the health benefits of walking can encourage older people to walk more, even if their neighborhood is considered less walkable than what is desirable, but no matter the encouragement and motivation, it is important to ensure that there are appropriate, agefriendly routes adequate to the walking behavior of older people, in order to support these health recommendations.

A reduction in performance is expected as people grow older, with the walking behavior of older people conveying the decline of their perceptive and motor-cognitive skills. This includes a decrease in visual capacity and hearing ability, loss of muscle strength and coordination, and longer reaction times. Reduced flexibility and an increasing difficulty in adjusting to new situations can lead to less attentiveness, all of which make the use of public road transport less preferable compared to other modes of transportationespecially walking [21-23]. Reduced mobility also means that older people tend to walk slower than younger people, for example when crossing the street [22]. Results obtained by Gorrini et al. [24] showed that older people are $22 \%$ slower than adults when crossing a street, on average. According to another study [25], older people walk $40 \%$ slower on an urban crowded walkway than younger adults. This can be problematic when, for example, pedestrian green light intervals are too short.

Furthermore, older people face many other barriers while walking. A study in Austria [26] revealed that many older people are impacted by the high speed of vehicles and the lack of crosswalks within walking distance. In addition, the bad quality of the sidewalk surface (i.e., cobblestones), their narrowness, and the cars parked on them constitute important obstacles. Low quality of public lighting and mixed sidewalks (i.e., open to bicycle use) can likewise make older people feel uncomfortable and unsafe [23,27].

Pedestrian areas with restricted vehicle traffic can support older people's mobility. Research from Japan [28] has evaluated the optimization of the traffic system in a historic city center-almost all vehicle lanes were modified to pedestrian-only and non-motorized, and parking was relegated to the underground. As a result, middle-aged and older people increased their leisure walking activity. The study supported the idea that traffic areas not restricted to motorized vehicles should be structured according to clear lines of division in order to support the mobility of other people, with areas for driving, walking, parking, and cycling up to $30 \mathrm{~km} / \mathrm{h}$. Urban furniture such as benches for resting, water taps, and public toilets can also improve the comfort of older people and increase their safety and well-being $[22,23,29]$. Likewise, paths with enhanced scenery and green spaces motivate older people to walk more [28,29].

The concretization of an accessible and walkable pedestrian network which meets these desirable characteristics can be difficult, especially in historical cities. The needs and limitations of older people do not necessarily match the built environment of historic 
centers nor their heritage preservation needs [26]. Furthermore, the diversity of historic centers and their characteristics-precisely one of the aspects that makes heritage valuablealso makes it difficult to generalize certain aspects of their built environments. Nevertheless, some similarities often appear between the historic centers of European cities, such as their compact form, narrow streets and sidewalks, somewhat dilapidated historic buildings, and the mix of building uses [30-32]. In particular, the lack of an adequate sidewalk width, the bad state of sidewalk conservation, and barriers like electric poles or signs can decrease walkability for older people.

Depending on the topography of a particular city, steep slopes can constitute another barrier [32]. Our 2020 article [13] presented a correlation between the heart rate of older people and different types of slopes. The heart rate maximum average (HRMA) during vigorous activity is expected to be $155 \mathrm{bpm}$ (beats per minute) at the age of 65 and $130 \mathrm{bpm}$ at the age of 90 . With moderate activity, the heart rate should be 50-85\% of the HRMA [33]. According to Mazuroski [34], walking slopes with an incline of 5\% (uphill) result in a high level of effort when walking and an average heart rate of $120 \mathrm{bmp}$ for older people.

Another issue present in historic city centers is the quality difference between road hierarchies, as demonstrated by Campisi, Canale, and Tesoriere's [32] case study on the walkability of the historic center of Enna, Italy, which considered criteria similar to the ones in this study. The sidewalks along the main street or near the best maintained buildings received high evaluations. The sidewalks along other main roads, on the other hand, were often in a mediocre state of maintenance, viewed negatively by the participants of the study. In fact, more than $30 \%$ of roads in the study area were not suitable for walking for reasons other than steep slopes, namely, their lack of sidewalks and maintenance.

Another particularity of historic centers pertains to urban space adjustments following the invention of the automobile, for example in the form of parking lots that now limit the quality of the pedestrian network. In their study of parking retrofit approaches, Bass and Livingston [30] stress that parking directly in front of buildings (whenever it is appropriate to the function of the street and ensures a balanced occupation of the space) can serve as a visual safety barrier between pedestrians and street traffic. It can also maintain a good connection between the buildings and the sidewalk.

As a last aspect regarding historic cities, there are several studies all over the world about the correlation between the onset of a World Heritage declaration process and the intensification of heritage tourism [35-39]. In the case of Porto, the city has invested in improving urban space since its declaration as a UNESCO World Heritage Site in 1996, and many old buildings are now used as restaurants, bars, or shops. At the same time, there are still roads that do not meet the needs of older people's mobility, most of them of second or third grade and with residential use [40]. Considering that the municipality of Porto, and its historic city center, has the highest rate of people aged 65 and above compared to the whole province, we were urged to evaluate its pedestrian network [41].

\section{Materials and Methods}

The study area corresponds to circa 20 ha. It is located in the historic center of Porto, with its selection resulting from specific aspects. Firstly, the city has a higher number of older inhabitants [41] when compared to the Portuguese average (22.1\%), with 28.33\% inhabitants aged 65 years or older in 2018. Furthermore, the population of Porto has been shrinking, from 237,591 inhabitants in 2011 to 216,606 inhabitants in 2019 [42]; this demographic change hints at a future increase in the number of older people living in the city. Such numbers highlight the relevance of studies on older people's walkability and health within this urban context, as well as the need for evaluating and adapting pedestrian networks to older people's needs. Secondly, in 1996 Porto received the classification of World Heritage Site for its centuries-old center of high integrity and identity [43]. Due to the characteristics of this built environment, further specified in the literature review, walkability information is in frequent demand by Porto citizens and tourists of all ages who visit the historic center on foot. Furthermore, the Municipality of Porto and other 
local entities have been investing in improvements to the quality of older people's lives within the city; in fact, in 2016 Porto was recognized as a reference site by the European Innovation Partnership on Active and Healthy Ageing (EIP-AHA) [44], and the Porto4 Aging consortium was built upon the shared vision and common target of improving responses to the citizens' needs-in particular, issues related to active and health aging in the Porto region. All of these expressions of interest in the subject make the application of the walkability index even more relevant.

Nevertheless, our previously conducted research [13] identified important difficulties pertaining to the characteristics of the historic center. Keeping in mind the high percentage of older people living in Porto, the chosen study area is located in a consolidated built environment that presents several challenges. Furthermore, the complexity of uses of buildings and types of public spaces in the area mean that the index variables must be carefully evaluated.

The timetable for this research was planned beforehand. The work started with conducting a brief literature review, in order to support the application of the WIEH to a real study area. The general and specific literature review was conducted mainly in October and November 2020, based on the previously determined conceptual design for application of the WIEH [13], as well as additional relevant and recent publications from Google Scholar, Web of Science, Science Direct, and the Scopus database in the humanities and social sciences. The review centered on older people's mobility, along with the walkability characteristics of historic city centers on older people's walkability and its correlation with health-due to our choice of case study, historic centers as meeting places constituted an important topic as well.

Fortunately, older people's mobility within the study area has been analyzed previously, in the context of the Mobi-Age research project [45], in which some of the authors had participated. The resulting data were incorporated into this study for the purpose of building an overview of the area and determining the starting point for fieldwork preparation. Fieldwork took place from November to December 2020. The missing data necessary for the WIEH calculation were collected on the use of every building in the study area, all public spaces, vegetation, streets and their sidewalks, the traffic management system, lightning, urban furniture, signs, stairs, and obstacles.

A basic map comprising the building cadaster and public roads of the study area was created using GIS software, more specifically QGIS, incorporating all the collected data after the fieldwork phase. This compilation was analyzed and presented with the help of the same software. Variables were categorized into three dimensions: urban tissue, urban scene, and safety. A more detailed description of every variable is presented in Section 4. To calculate the WIEH, two indices were used: the 'index of space walkability' ('isw') and the 'index of slopes and stairs' ('is'). Both were calculated using GIS software, with the detailed description of this process presented in Section 4 of this work.

During the last step, which took place in January and February 2021, the collected data were evaluated and interpreted. Based on the index application results, in this article we provide a proposal to improve public space adequacy for older people. This proposal was categorized according to the same three areas as the data collection. Originally, results were meant to undergo testing and verification through the implementation of walking activities for older people throughout the study area; however, due to the COVID pandemic, this aspect of the study could not be put into practice.

\section{The Application of the WIEH to the Historic Center of Porto}

The application of the walkability index for elderly health (WIEH) to the historic center of Porto (Figure 1) followed the procedural steps described by the fifth point of the 2020 article [13]: (1) the pedestrian network was classified and validated as the basis for calculating the 'index of space walkability', or 'isw'; (2) the slopes and stairs of the study area were classified and used to calculate the 'index of slopes and stairs', or 'is'. The combination of these two indices led to the determination of the WIEH. 


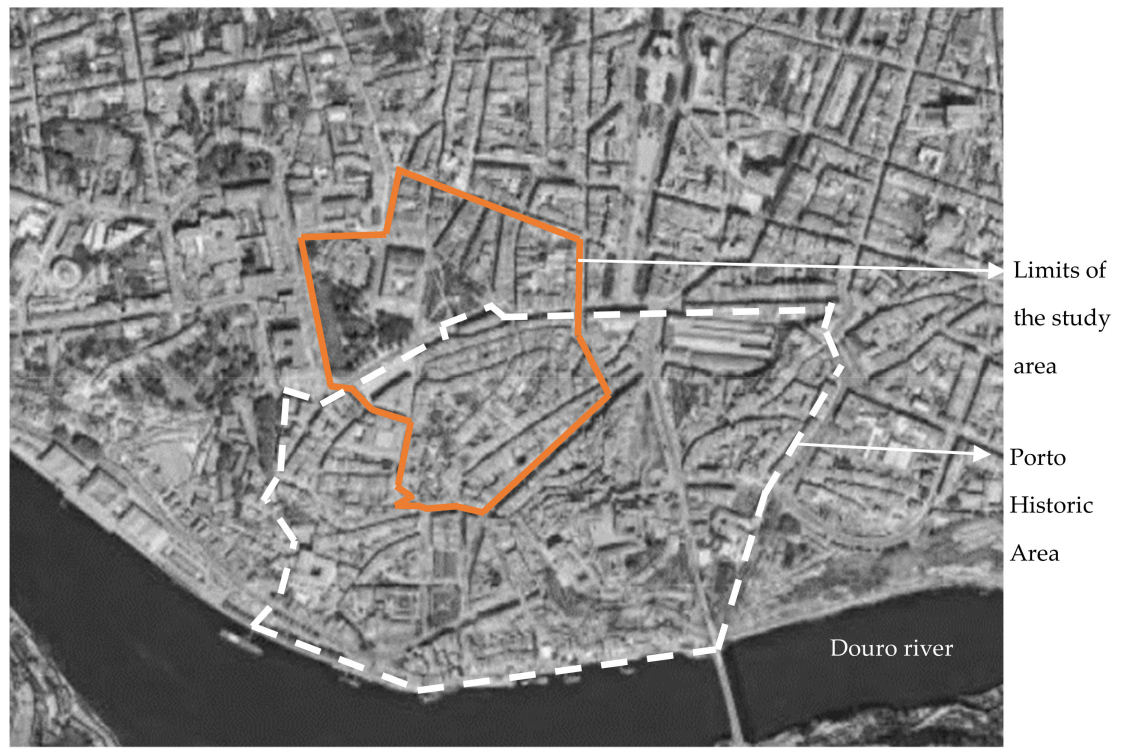

Figure 1. Limits of the study area. Source: https:/ /www.google.pt/maps/@41.1438384,-8.6149281,1969m/data=!3m1!1e3 (accessed on 4 February 2021).

Thus, for the purpose of calculating these indices, the following data resources-which were publicly available and supplied by the Mobi-Age research project, as described in the methodology section-were used in addition to the information compiled in the 2020 article: the building cadaster for the study area [46], statistical data regarding its population, and its elevation profile. The remaining necessary data were collected during the fieldwork phase of this research, from 16 November to 27 December 2020. Figure 2 presents some pedestrian spaces in the study area.

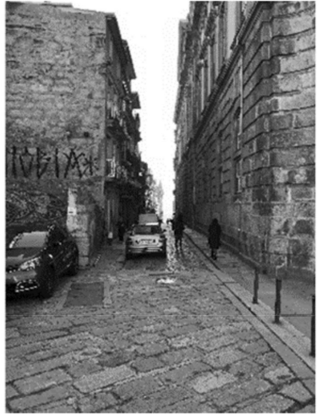

(a)

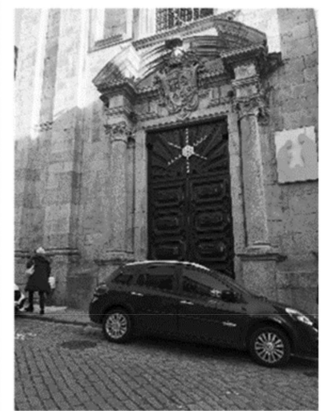

(b)

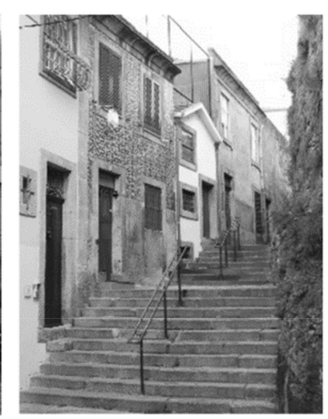

(c)

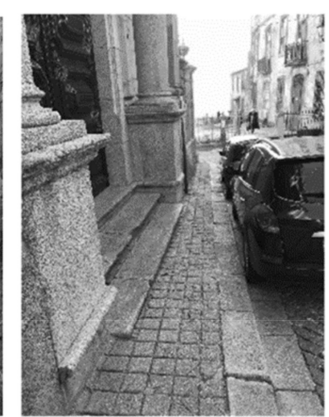

(d)

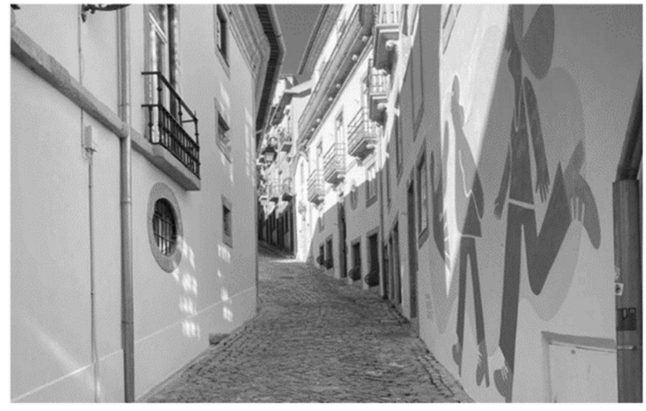

(e)

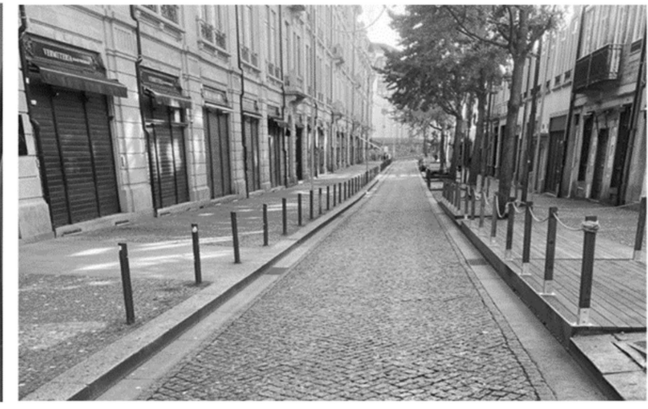

(f)

Figure 2. (a-f) Some examples of the pedestrian network in the study area of Porto. Source: (a-d)—adapted from Master Programe/FEU Course Group “Triangulation”, 2019; (e,f)—authors' archive. 
As a first step, all information pertaining to the pedestrian network under study was reviewed and systematically classified into three dimensions: urban tissue, urban scene, and safety. Afterwards, all variables were evaluated and rated from one (the lowest rating) to three (the highest rating). Figure 2 provides some examples of the different pedestrian paths within the study area.

Regarding the first systematic dimension — urban tissue-several variables were answered or calculated based on the specificities of the case study and the available data. The pedestrian surface quality (PSQ) of the study area was mostly good (55\%). The surface quality of $28 \%$ of the pedestrian network was at an acceptable level, whereas $17 \%$ was of bad quality. Within the variable 'sidewalk existence and width' (SEW), the categorization was complemented by the existing pedestrian zones with no visible sidewalks, with the respective streets receiving a rating of three, and 'traffic street intersections' ('TSI') in the study area were evaluated for each sidewalk. In the category 'existence of stairs' (EoS), seven stairs were registered. Regarding the variable 'existence of obstacles' (EoO), disturbing elements and severely narrow sidewalks were found. The 'land use mix' (LUM) of the existing buildings was divided into seven categories (Table 1).

Table 1. Land use mix of the study area.

\begin{tabular}{cc}
\hline Land Use & Number of Buildings \\
\hline Churches & 3 \\
Public buildings (university, museums, government buildings) & 9 \\
Medical facilities & 12 \\
Banks & 3 \\
Grocery stores and shops & 214 \\
Cafes, bars, and restaurants & 196 \\
Residential use (only) & 135 \\
\hline
\end{tabular}

In total, 572 buildings within the study area were categorized. It is important to note that most of the buildings had more than one use. More specifically, 417 of the buildings - and thus, nearly all of them-other than those solely for residential use also serve a residential purpose, in addition to the uses categorized in Table 1.

The second systematic dimension-urban scene-includes two variables: 'existence of trees/vegetation' (ETV) and 'existence of urban furniture' (EUF). Sidewalks with trees received a rating of three, whereas sidewalks across the street were rated two when profiting from the shadow of those same trees. Considering this, 37 sidewalks were rated as having strong vegetation, 12 were classified as moderate, and 83 sidewalks had no trees or other vegetation. Urban furniture, on the other hand, was classified according to the five following topics (Table 2).

Table 2. Classification of urban furniture.

\begin{tabular}{cc}
\hline Urban Furniture & Total Number \\
\hline Benches & 83 \\
Water taps & 3 \\
Phone booths & 1 \\
Public toilets & 1 \\
Bus stops & 7 \\
\hline
\end{tabular}

Concerning the variables of the third systematic dimension-safety-the 'street light quality' (SLQ) of the study area was mostly good (55\%); 37 sidewalks $(28 \%)$ had an acceptable street light quality, whereas the lighting of 22 sidewalks (17\%) was in bad condition. The 'diversity of information signs' (DIS) received a very low rating for the whole study area, with only three signs being registered.

In total, data elements pertaining to 132 sidewalks were collected, including the pedestrian network along the streets, streets without any marked sidewalks, and footpaths, 
e.g., through parks. Traffic street intersections, or the intersections of two sidewalks or footpaths, were decisive for the division of the sidewalk segments. In a few cases, those sidewalk segments had to be differentiated again because of their different slopes.

\subsection{The Index of Space Walkability (ISW)}

Based on the preliminary analysis per dimension, the index of space walkability (isw) was calculated, according to the following formula:

isw $=$ Urban Tissue variables $\times 0 \%+$ Urban Scene variables $\times 16 \%+$ Safety variables $\times 24 \%$

$$
\begin{gathered}
\text { isw }=(\mathrm{PSQ} \times 0.08+\mathrm{SE} \times 0.06+\mathrm{SW} \times 0.06+\mathrm{TSI} \times 0.12+\mathrm{EoS} \times 0.08+\mathrm{EoO} \times 0.12+\mathrm{LUM} \times 0.08) \\
+(\mathrm{ETV}+\mathrm{EUF}) \times 0.08+(\mathrm{SLQ}+\mathrm{DIS}) \times 0.12
\end{gathered}
$$

The results of the isw calculations for each sidewalk varied between 1.48 (a sidewalk that was not suitable) and 2.76 (the most suitable sidewalk of the study area). Out of the total of 132 sidewalks in the study area, only the abovementioned 1.48-rated sidewalk was not suitable. Thirty-nine percent of sidewalks were deemed to be less suitable, $67 \%$ were considered suitable, and only $3 \%$, comprising a total of four sidewalks, fell into the category of most suitable (Table 3).

Table 3. Results of the application of the index of space suitability for walking (isw).

\begin{tabular}{ccc}
\hline Index Values (ISW) & Description & Number of Sidewalks within the Study Area \\
\hline $1-1.49$ & Not suitable & 1 \\
$1.5-1.99$ & Less suitable & 38 \\
$2-2.49$ & Suitable & 84 \\
$2.5-3$ & Most suitable & 4 \\
\hline
\end{tabular}

With the use of GIS software, the pedestrian network was visually represented through the following map (Figure 3).

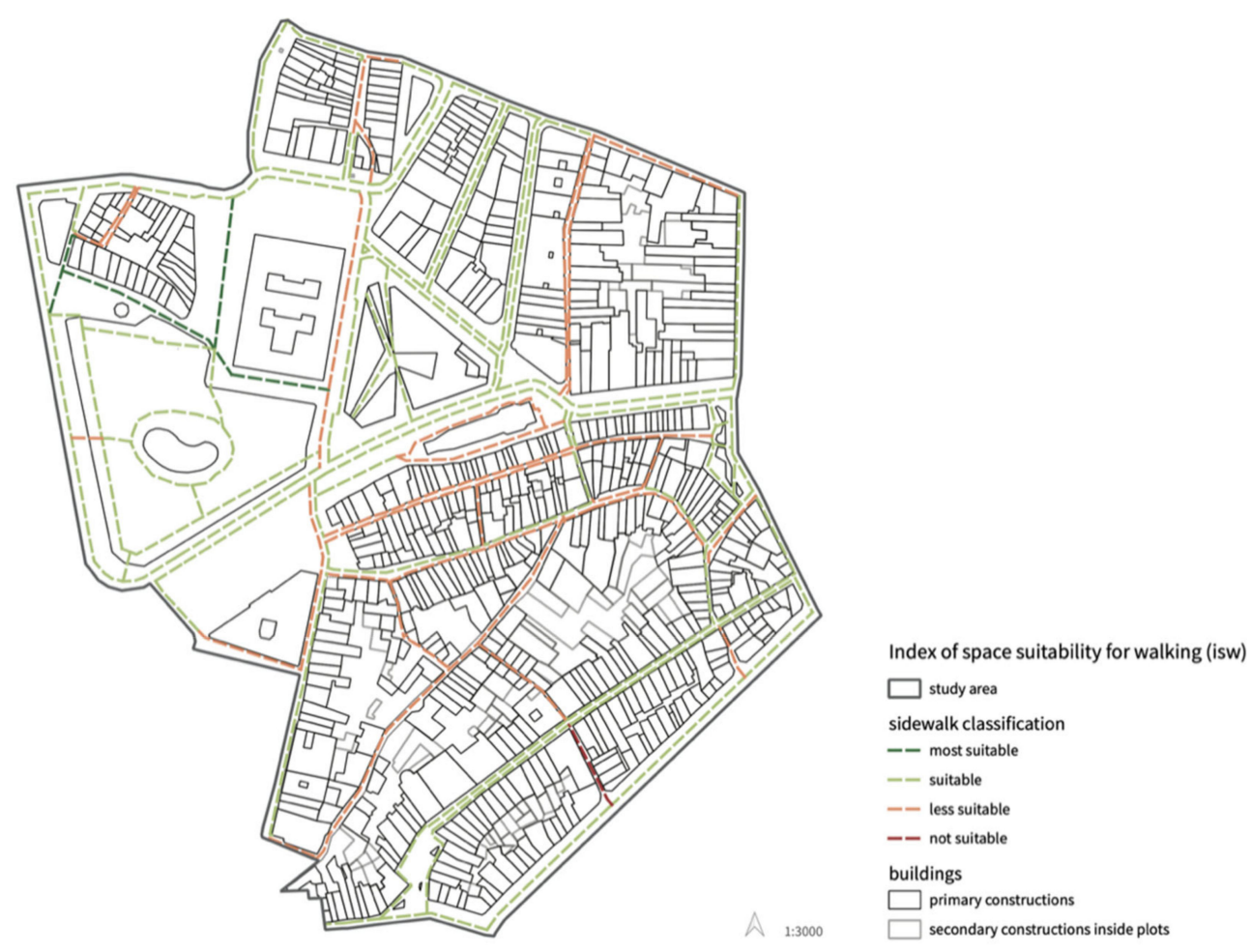

Figure 3. Pedestrian network classification according to the index of space suitability for walking (isw). 
Looking at the spatial distribution of sidewalks, those classified as suitable and most suitable for older people were concentrated in the northwestern and southern parts of the study area, whereas sidewalks deemed less suitable and not suitable were mostly located in the center of the study area, which had a high percentage of residential land use. Suitable sidewalks located in the southern part had already undergone improvements financed by the municipality of Porto, which means they were in good condition and appropriate for older people's walking activities.

\subsection{The Index of Slopes and Stairs (IS)}

For the purpose of calculating the index of slopes and stairs (is), all slopes and stairs identified within the study area were classified. Stairs with at least three steps were considered, in a total of seven occurrences. Slopes were calculated using topographic contour lines, superimposed on each sidewalk of the study area. During the 2020 study [13], an analysis of the correlation between slopes and the heart rate of older people was already undertaken, as previously explained in Section 2. According to that analysis, slopes $<5 \%$ were considered suitable, slopes with an incline between $5 \%$ and $8 \%$ were acceptable, and slopes $>8 \%$ were steep and thus not recommended for older people.

Based on the classification of sidewalks following these parameters, the index of slopes and stairs (is) was calculated. Results varied between one (suitable slopes and no stairs) and four (steep slopes and a large number of stairs). In the instances where the categorization of slopes and the number of stairs did not match, the worst variable was decisive, e.g., sidewalks with steep slopes but no stairs received an evaluation of four in the index.

Table 4 shows the results of the index of slopes and stairs (is) calculations. The pedestrian network of the study area comprised 132 sidewalks, with $50 \%$ labeled as most recommended, $27 \%$ as less recommended, and $23 \%$ of sidewalks as not recommended.

Table 4. Results of the application of the index of slopes and stairs (is).

\begin{tabular}{|c|c|c|c|c|}
\hline $\begin{array}{c}\text { Index } \\
\text { Values (Is) }\end{array}$ & Slopes & Stairs & Description & $\begin{array}{l}\text { Number of Sidewalks } \\
\text { within the Study Area }\end{array}$ \\
\hline 1 & $<5 \%$ & No stairs & $\begin{array}{c}\text { Most } \\
\text { recommended }\end{array}$ & 66 \\
\hline 2 & $<5 \%$ & Stairs/small number of stairs & Recommended & 0 \\
\hline 3 & $5-8 \%$ & $\begin{array}{c}\text { Stairs/significant number of } \\
\text { stairs }\end{array}$ & $\begin{array}{l}\text { Less } \\
\text { recommended }\end{array}$ & 35 \\
\hline 4 & $>8 \%$ & Stairs/large number of stairs & Not recommended & 31 \\
\hline
\end{tabular}

Again, data resulting from the application of this index were mapped using GIS software (Figure 4). It can be observed that sidewalks in the southern half of the study area tended to be less recommended or not recommended, echoing the isw results for that same area. Additionally, previously suitable sidewalks were no longer recommended due to their steep slopes and/or large number of stairs, e.g., the sidewalk in the southernmost part of the study area. As explained, slopes and stairs are extremely decisive for older people's walkability.

According to the index of slopes and stairs, fewer sidewalks were deemed suitable for older people when compared to the isw results. In total, 50\% of the pedestrian network under study was less recommended or not recommended. Sidewalks classified as not recommended for older people were not included in the following final step; in other words, 31 sidewalks (23\% of the pedestrian network) did not meet the needs of older people. 


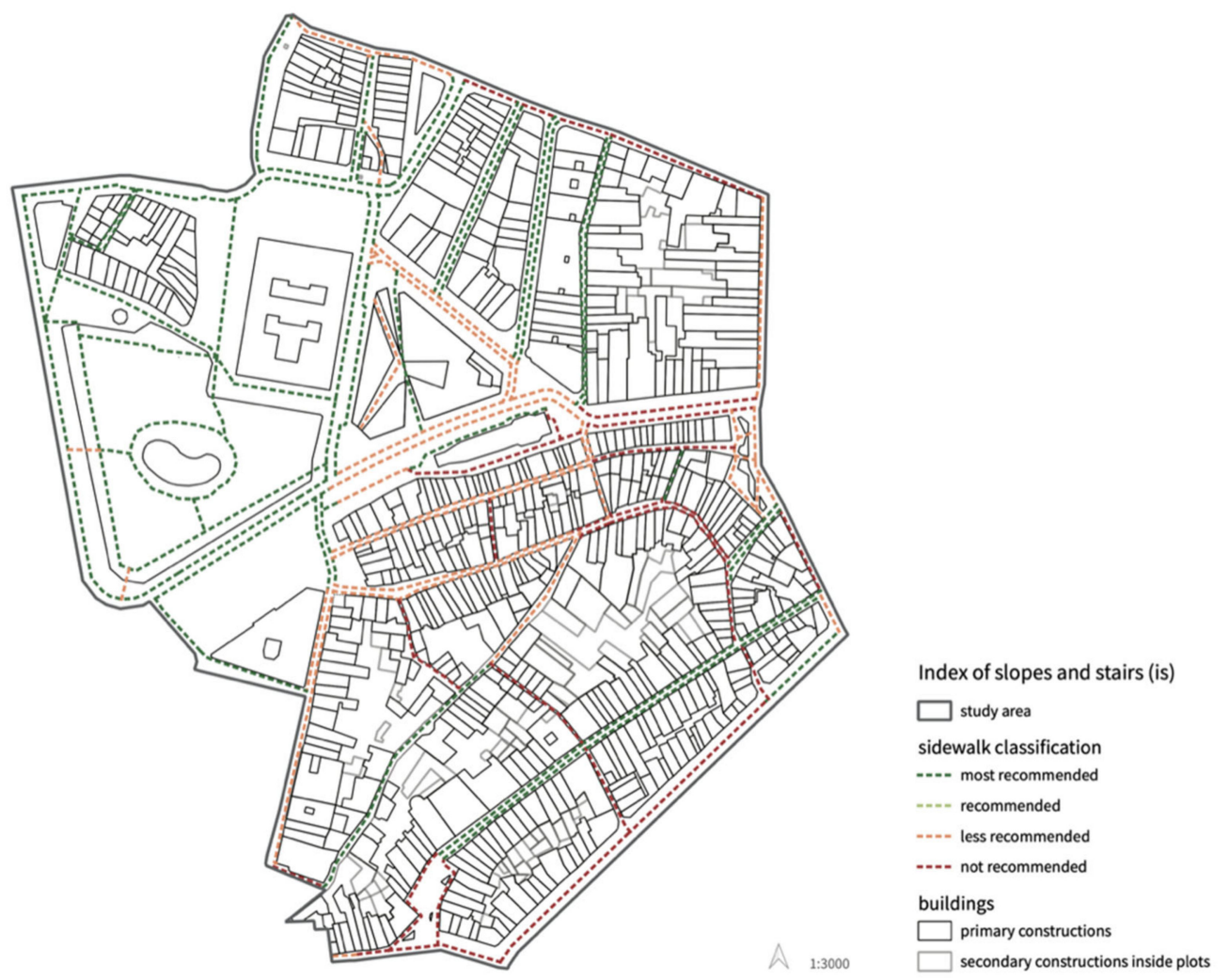

Figure 4. Pedestrian network classification according to the index of slopes and stairs (is).

\subsection{The Walkability Index for Elderly Health (WIEH)}

Based on the two indices above, it was possible to calculate the walkability index for elderly health (WIEH) using the following formula:

$$
\text { WIEH }=\text { isw } / \text { is }
$$

The lowest value of this index was 0.4 , corresponding to a pedestrian path located in 'Travessa do Ferraz', in the southwest of the study area; this path was not age-friendly and not recommended at all. In total, 21 out of 132 sidewalks fell into the worst category (16\%). Thirty-four percent of sidewalks were less age-friendly and should be avoided because of their unsuitable pedestrian quality and/or the inexistence of acceptable slopes and stairs. Sixty-three sidewalks, or $48 \%$ of the pedestrian network, were reasonably age-friendly and could be considered good routes for walking. Only $2 \%$ of sidewalks had an index value between 2.5 and 3 and were thus highly recommended (Table 5).

Table 5. Results of the application of the walkability index for elderly health (WIEH).

\begin{tabular}{|c|c|c|c|}
\hline WIEH & Description & Observation & $\begin{array}{c}\text { Number of } \\
\text { Sidewalks within } \\
\text { the Study Area }\end{array}$ \\
\hline$\leq 0.5$ & Not age-friendly & $\begin{array}{l}\text { Routes that are not at all } \\
\text { recommended }\end{array}$ & 21 \\
\hline$>0.5$ and $\leq 1$ & Less age-friendly & $\begin{array}{c}\text { Routes that should be } \\
\text { avoided }\end{array}$ & 45 \\
\hline$>1$ and $\leq 2.5$ & $\begin{array}{l}\text { Reasonable } \\
\text { age-friendly }\end{array}$ & $\begin{array}{l}\text { Routes that can be } \\
\text { considered }\end{array}$ & 63 \\
\hline$>2.5$ and $\leq 3$ & More age-friendly & $\begin{array}{l}\text { Routes that are highly } \\
\text { recommended }\end{array}$ & 3 \\
\hline
\end{tabular}


The following map (Figure 5) shows that routes with the highest index value were concentrated in the northwestern part of the study area. The routes that were not agefriendly fell in the southern half of the area, which mostly corresponded to the narrow streets of the historic center.

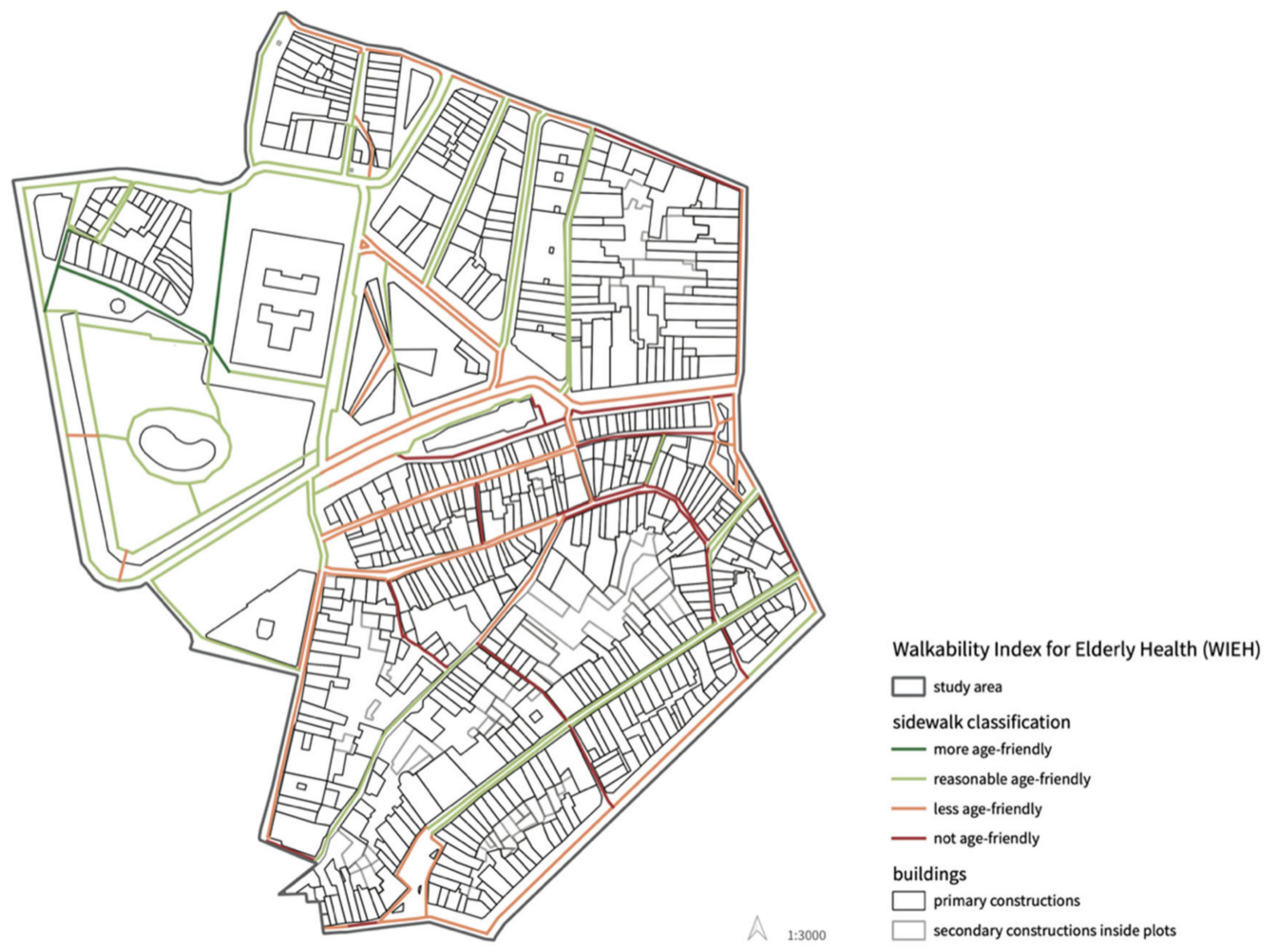

Figure 5. Pedestrian network classification according to the walkability index for elderly health (WIEH).

\section{Discussion of Results}

The results demonstrate that only a few sidewalks and footpaths within the study area can be classified as age-friendly. The topography of the area is the main culprit, resulting in a significant number of steep slopes, which affected $23 \%$ of the total paths. Moreover, most pedestrian paths did not meet the needs of older people due to a lack of vegetation (shade) and urban furniture on the one hand, and/or the poor maintenance of the sidewalk surface and the lack of proper sidewalks on the other. Figure 6 presents an example of a 'more age-friendly' street, followed by its counterpoint-a street categorized as 'non-age-friendly' in Figure 7. The localization of both examples is pointed out in Figure 8, with the former located in the upper area, which underwent an urban requalification program when Porto was elected European Capital of Culture in 2001; whereas the latter illustrates the strong heritage of the medieval morphology in the historic center.

Regarding individual variables, the 'diversity of information signs' (DIS) corresponded to the lowest rankings, whereas 'land use mix' (LUM) received some of the highest classifications. Furthermore, the evaluation of 'existence of obstacles' (EoO) revealed very good results. 


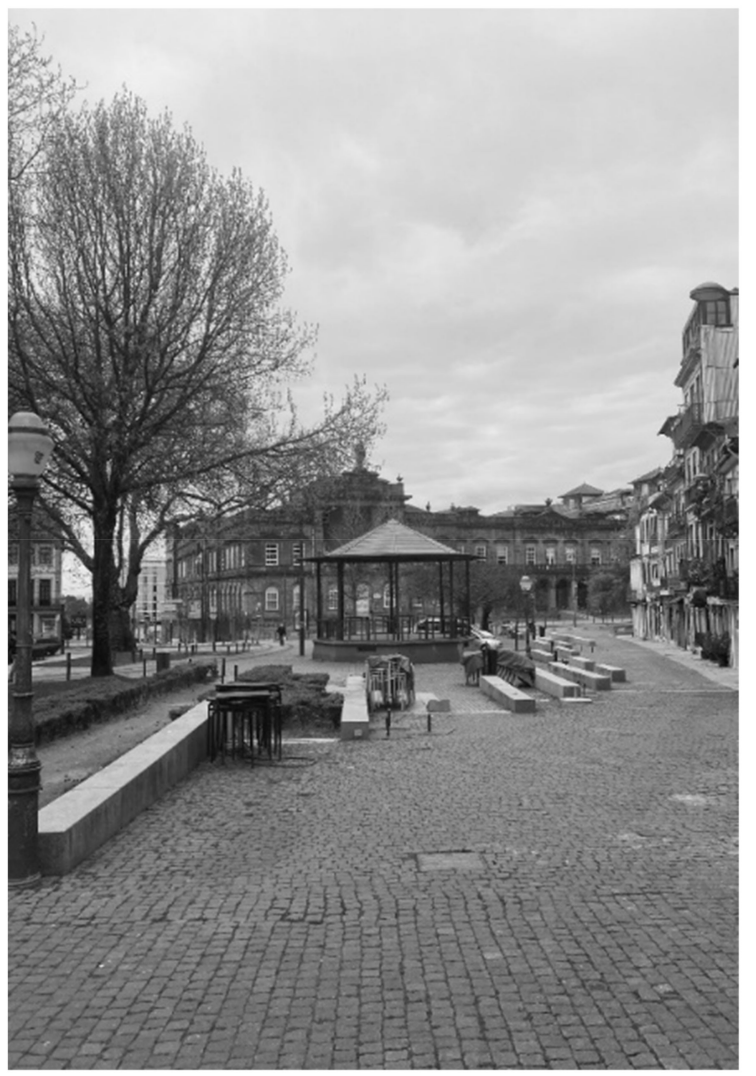

Figure 6. Example of a more age-friendly route: Square 'Campo Mártires da Pátria'.

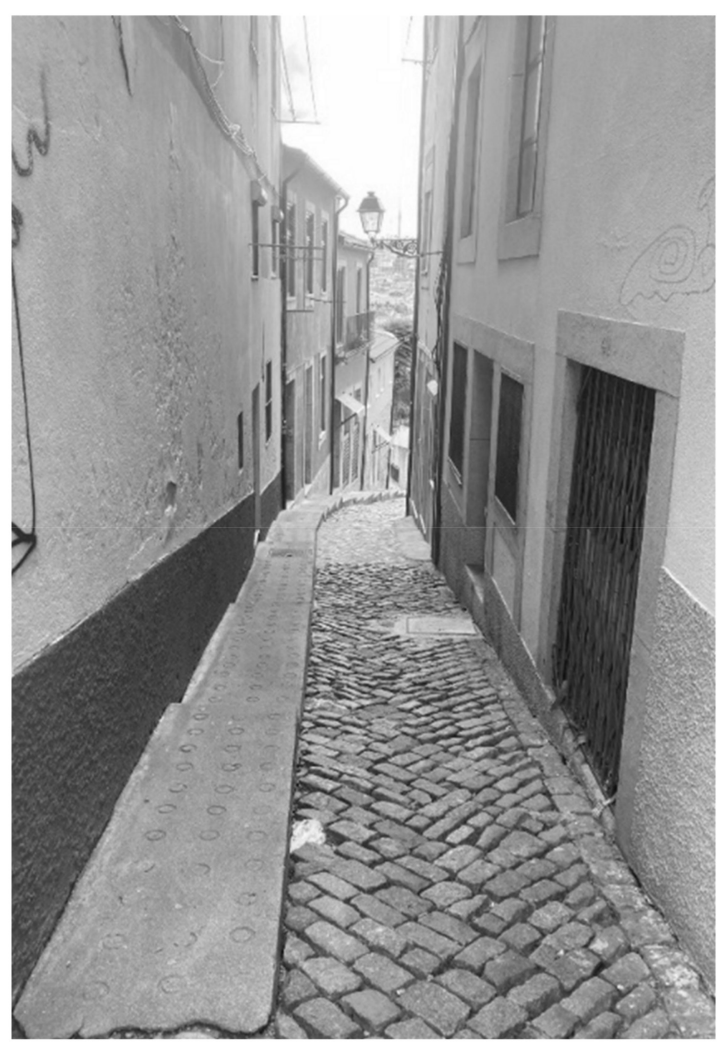

Figure 7. Example of a non-age-friendly route: Street 'Travessa do Ferraz'. 


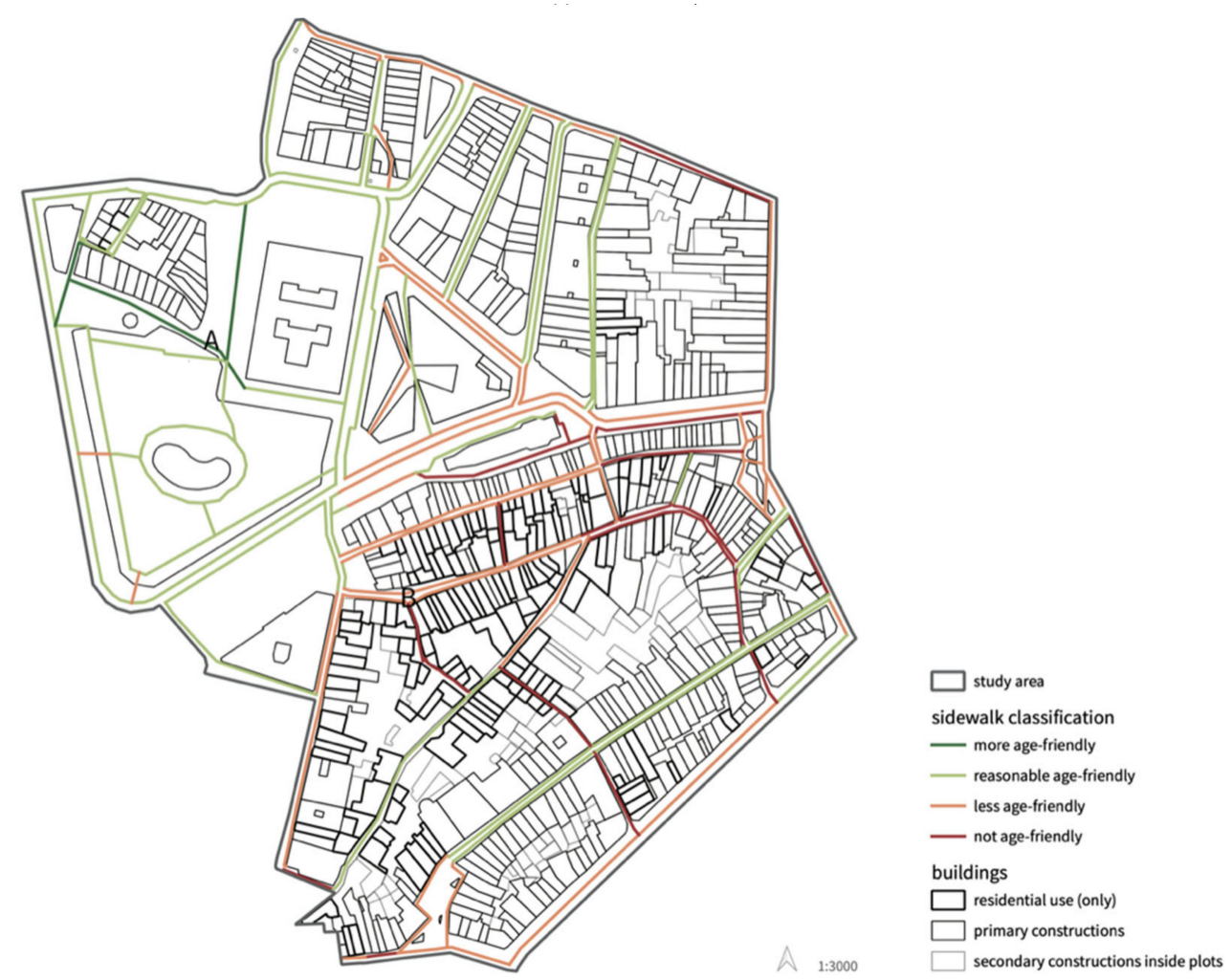

Figure 8. Pedestrian network classification according to the WIEH, and correlation with residential use.

Pedestrian paths which were not recommended for older people's walkability and health needs were situated in the historic area, a situation which has not improved during the last decades, nor has it accompanied the significant growth in tourism-related activities. These results echo the outcomes of the study undertaken by Campisi, Canale, and Tesoriere [32], previously presented in Section 3. Especially noticeably, the area with the least suitable pedestrian network had the highest residential use (Figure 8). To highlight the gravity of the situation, it should be remembered that the resident population of the area mostly consists of older people.

Other noteworthy results include the fact that, in streets with a higher variety of land use, the space suitability is generally better. In general, only in the sections of pedestrian paths corresponding to steep slopes is this suitability overturned. Nevertheless, when looking at the correlation between heartrate and existing slopes, the steepness of $50 \%$ of the pedestrian network within the study area was greater than $5 \%$, which would require older people to expend at least a moderate walking effort, with a correspondingly high heart rate.

These results raise the question of whether (and how) an age-friendly pedestrian network can be achieved in the historical area of Porto, considering the high influences of its slopes on its walkability, an aspect which obviously cannot be changed. This challenge is explored in the next section, using a proposal format.

\section{Proposals}

The focus of the following proposals is the improvement of the adequacy of public spaces for older people's walkability, through urban design adjustments. Mirroring the diagnosis methodology, proposals are categorized into the same three systematic dimensions: urban tissue, urban scene, and safety. The proposed drawings are schematic drawings concerning spaces' adequacy of walkability and are not intended to detail other aspects that could also subsidize the improvement of public spaces (i.e., thermal comfort and climate-adapted design). Rather, they are intended to illustrate, in a simple way, how small 
interventions (which can be easily implemented by municipal services) are sufficient to significantly improve the most inadequate spaces for older people's walkability.

In the first category - urban tissue - the variables of 'sidewalk existence and width' (SEW) and 'pedestrian street quality' (PSQ) present the most opportunities for adjustments. Especially in the southern part of the study area, comprising mostly narrow streets and sidewalks, space for walking is limited. Therefore, a 'shared space' is proposed for this area (Figure 9). According to this model, the hierarchy between pedestrians and vehicles is abolished; streets would be used by vehicles, always at low speeds, with no visual nor built elements separating different users [47], which would include pedestrians, cyclists, and motorized vehicles. Narrow sidewalks in poor condition, an obstacle to walkability, would be removed to make space for walking; in other words, pedestrians would be able to use the complete width of the street, coexisting with traffic.

During the data collection phase, some streets with no separate lanes for pedestrians, bicycles, and motorized vehicles were identified, which could constitute a starting point for an official shared space, which would not differ much from their current use. Once the concept became more well-known and accepted, it would be possible to widen its application to other streets in the study area (Figure 9: area marked in grey). This would represent an improvement to the pedestrian network, while preserving the historic scenery with its narrow streets.

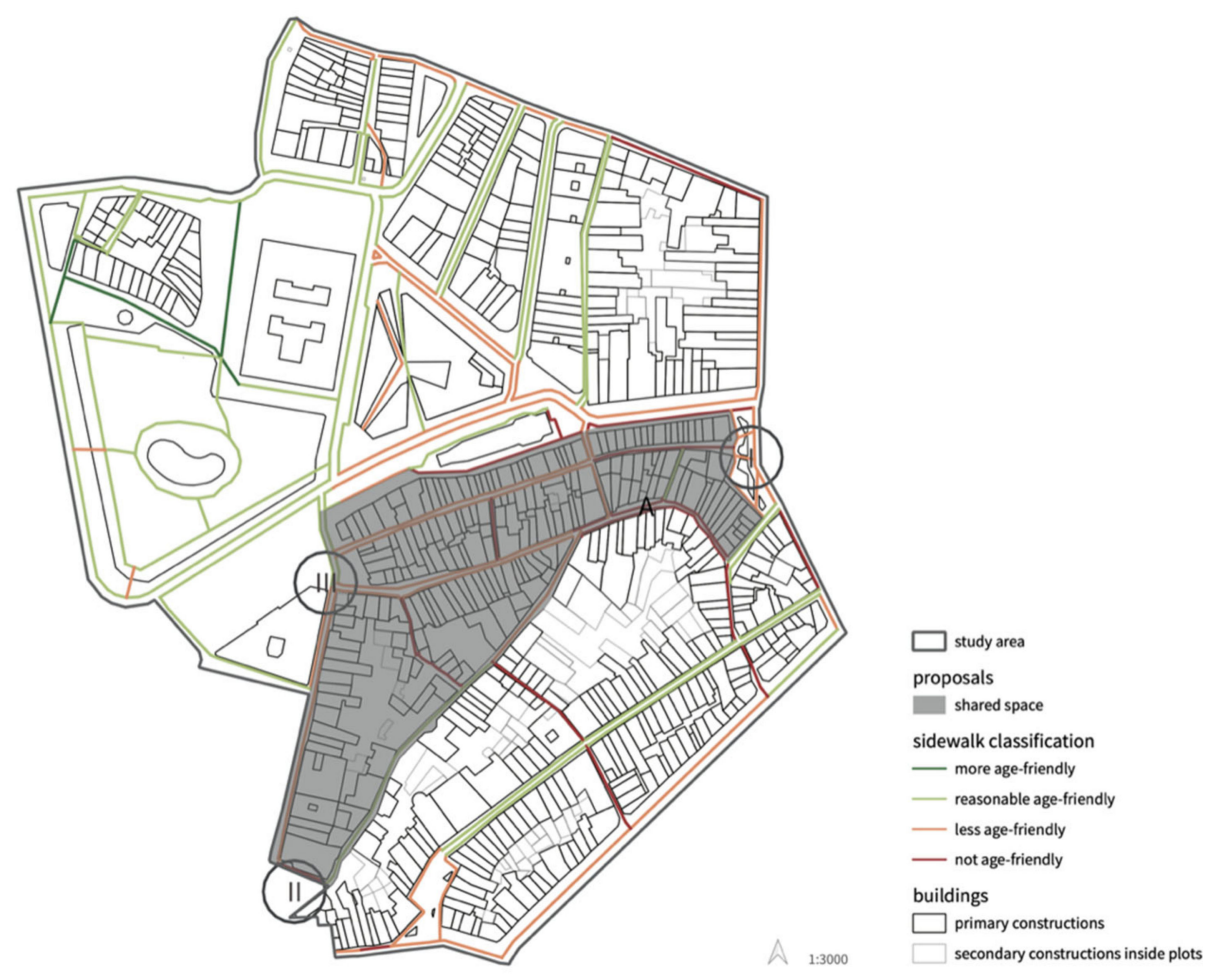

Figure 9. Proposals based on the WIEH.

Although the available literature shows that transforming city center areas into shared spaces can increase pedestrian activity and dwell time, with the speed of motorized vehicles tending to decrease and pedestrians moving more safely [48,49], differences between the designs of the urban shared space model and the specific needs of older people must also be taken into account. A form of conciliating these two aspects is the creation of 'safe zones' which are completely restricted to motorized vehicles. The boundaries of these safe zones are physically represented by lines, guaranteeing a safe and comfortable walking experience for older people, particularly those who are visually limited [49,50].

This approach can provide an opportunity for residents and visitors to appropriate street spaces according to their own needs, i.e., for recreational and healthy walking, 
without enforcing certain uses. As a requirement to ensure an inclusive use of these shared areas, surface materials must meet the needs of older people, while respecting the historic scenery, and shared areas have to be clearly marked.

The shared space model could also be supplemented with appropriate urban furniture and vegetation, an improvement pertaining to the second systematic area-urban scene. Figure 10a illustrates the current state of 'Rua dos Caldeireiros', of which the location is marked in Figure 9 with an "A". The sidewalks are quite narrow and in bad condition, with a lot of space occupied by parked cars. Furthermore, this street is less recommended for older people due to its steep slopes. Figure 10b renders a proposed transformation of the same street section into a shared space; the design includes benches with integrated vegetation and a uniform and distinctive sidewalk surface material (granitic stone), which would center the importance of pedestrians in the shared space, with the surface color marking the shared area.

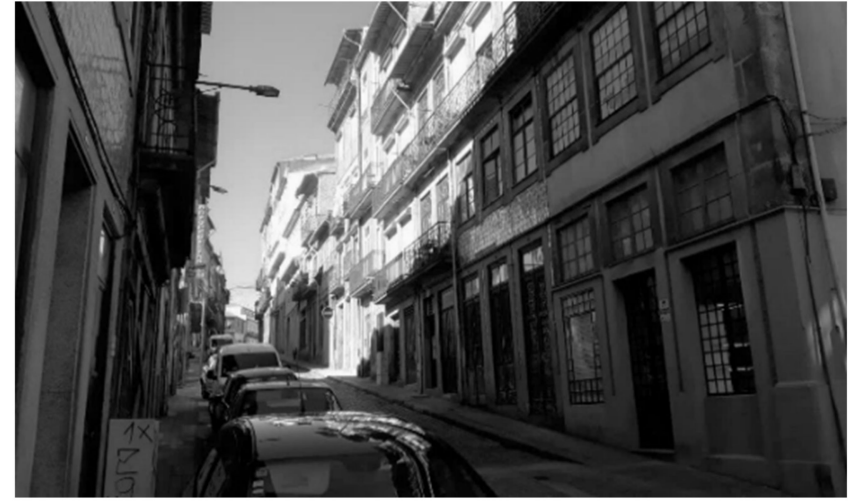

(a)

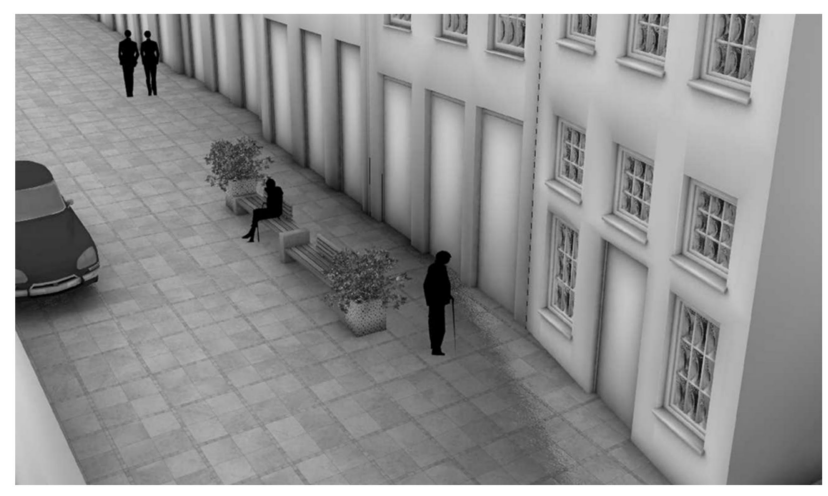

(b)

Figure 10. Street 'Rua dos Caldeireiros' in the historic city center of Porto. (a) Current situation; (b) proposal.

This design allows older people to use the street more comfortably despite its steep slopes, due to improved surface walkability and benches which ensure opportunities for resting between stretches of walking. Furthermore, since the cross sections of other historic streets in the study area (Figure 9: area marked in grey) are similar, this example of a redesigned street space with urban furniture could be implemented in other streets.

Figure 11 illustrates a simulation for the street 'Conde de Vizela'. The new public space layout (simulation) prioritizes pedestrians by supplying more space for them, through the unification of the street surface material. Furthermore, some furniture can be provided in this shared scenario. The height of the sidewalk was removed, increasing walking safety. Even so, vehicles can have conditioned access to the street for emergency services, loading and unloading, etc.

Within the study area, there are also public spaces which already have good vegetation levels, and thus should also be provided with urban furniture, benches in particular, in order to increase dwell time. Potential candidates include 'Largo dos Loios' (Figure 9: circle I), located in the eastern part of the study area, and the square next to 'Rua da Bataria' (Figure 9: circle II), which is adjacent to the study area but could easily be included in walking routes for older people. Next to the museum, 'Largo Amor de Perdição' (Figure 9: circle III) could easily be upgraded by planting more trees and vegetation near the existing benches (Figure 12a,b). Another important point is that if these public places were connected by a suitable pedestrian network (for example, using the shared space model), older people could use them both as a walking destination and as places to rest after walking up the steep slopes surrounding the area. 




(a)



(b)

Figure 11. Street 'Conde de Vizela' in the historic city center of Porto. (a) Current situation; (b) proposal. Source: adapted from Master Programe/FEU Course Group “Making Place”, 2019.

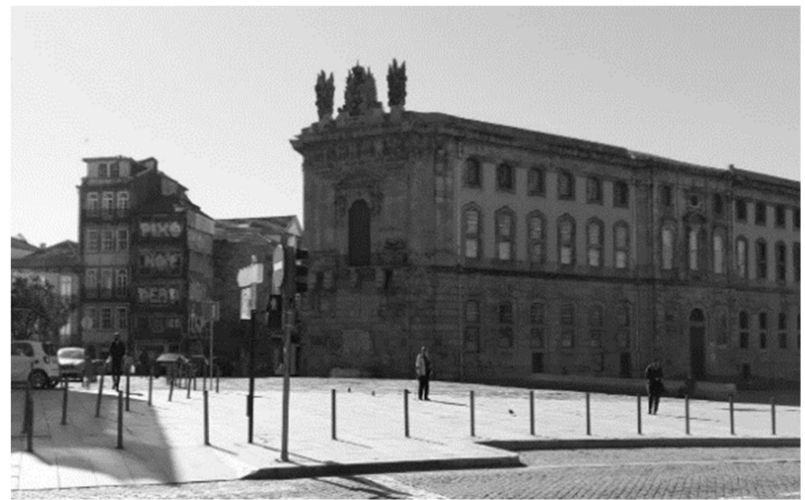

(a)

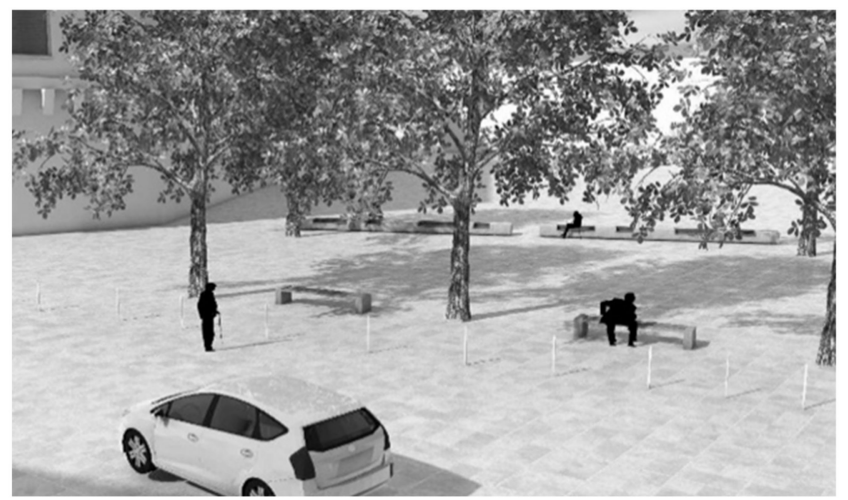

(b)

Figure 12. 'Largo Amor de Perdição'. (a) Current situation; (b) proposal for space redesign with trees and benches.

Turning to the 'safety' dimension, there were generally enough streetlights in the study area. However, during the data collection phase, a few of those lights were marked as damaged or inappropriate, and thus did not sufficiently illuminate pedestrian paths. A simple measure for correcting this issue is the implementation of regular checks or a reporting system. Another important aspect of this systematic dimension is the existence of information signs, which was lacking within the study area. Therefore, in this work, we propose the creation of a 'health route' traversing the study area, adequately signaled within the physical space. Through appealing and adequate signs, older people (and any other interested group) can be provided with motivation to increase their walking activity. In addition to an easy-to-read design, these signs should be informative, pointing out the health benefits of walking, the level of effort that is needed for certain sections of the route, providing orientation within the city, and disseminating information on cultural heritage. Together with the upgraded public spaces and pedestrian paths from previous proposal points, this 'health route' contributes to improving walkability for older people, turning obstacles (steep slopes) into opportunities to retain a good level of health in a creative way. The route can be developed in cooperation with local actors such as the university (design and urban development), artists, and the older residents themselves.

Most of these proposals can be implemented with little effort, as they are cost-efficient and aim at the short-term. In spite of this, their estimated effect on the walkability and 
health of older people is high. Concerning the long-term future, further plans must be devised, not only for the study area but for the whole city of Porto.

\section{Conclusions and Recommendations}

The results obtained from the application of the WIEH correspond to the general first impression of the study area and provide a detailed breakdown of factors influencing older people's mobility and health.

Within the study area, located in Porto, two main sub-areas were observed: first, the historic area, with stronger structural problems requiring a more radical intervention in the future; and secondly, the upper downtown, which underwent an urban requalification process in the past (in the scope of Porto's status as the European Capital of Culture in 2001) and of which the current problems can be more easily solved. In the latter, the proposed improvements aim at upgrading the area and empowering its residents, mainly by providing it with adequate urban furniture.

The presented variables, together with an evaluation ranging between a value of one and three, constitute an appropriate guideline, while at the same time leaving room for individual interpretations. Therefore, this paper exemplifies how the walkability index for elderly health (WIEH) can be easily applied to various study areas characterized by different urban designs and built environments. Cities with a similar medieval structure, in particular, could find similarities amidst the data collection, the application process, and the results of the WIEH. As shown, some improvements to public space require relatively low effort and few resources. However, the resulting benefits for older people's walkability could be significant.

The presented proposals can be taken into consideration or adapted to the specific needs and requirements of each city, mainly through their respective divisions, for municipal planning and design. Nevertheless, beyond the promotion of walkability as a general principle, there are aspects of this work that can be implemented by social institutions and agents, namely, concerning the transferability of useful information to older people and the selection of age-friendly paths for their daily outdoor routines.

The application of the WIEH to an urban area in Porto has therefore demonstrated the two main purposes of this index:

- A support tool for municipalities, allowing planning and design divisions to better understand the limitations public spaces impose on older people's walkability.

- An operational tool for users (mainly the older people themselves), enabling them to select the best paths for walking activities around the city.

This work also shows that the use of any GIS software is strongly recommended when working on collected data within this research topic, as the resulting graphic presentation provides an intuitive and appealing overview of results and their connections.

In future research, it would be interesting to collect data in cooperation with older residents, in a process of co-creation-researching with older people, not just for older people. Although the researchers intended to consult older people, the COVID-19 pandemic hampered the available opportunities and limited the fieldwork. This cooperation is important in order to obtain a more comprehensive perspective on the subject under study, and to determine whether older people hold differing impressions regarding the evaluation of the variables researched in this work.

One relevant aspect that ought to be clarified is the actual walking effort required by steep slopes-are the residents of Porto already used to walking steep slopes, and if so can it be said that they enjoy a better state of health? Another possibility for future research would be the testing of WIEH-recommended routes with the direct participation of older people, both to validate the evaluation methodology of this study against older people's impressions and perceptions, and to devise more efficient and adequate improvements for pedestrian paths. 
Author Contributions: Conceptualization, F.A. and S.C.; methodology, F.A. and S.C.; software, S.R. and T.S.; validation, F.A., S.C., S.R., and T.S.; formal analysis, F.A. and S.C.; investigation, F.A., S.C., S.R., and T.S.; resources, F.A., S.C., S.R., and T.S.; data curation, F.A., S.C., S.R., and T.S.; writingoriginal draft preparation, F.A., S.C., S.R., and T.S.; writing-review and editing, F.A. and S.C.; visualization, F.A., S.C., S.R., and T.S.; supervision, F.A. and S.C.; project administration, F.A. and S.C. All authors have read and agreed to the published version of the manuscript.

Funding: This research received no external funding.

Institutional Review Board Statement: Not applicable.

Informed Consent Statement: Not applicable.

Data Availability Statement: Not applicable.

Conflicts of Interest: The authors declare no conflict of interest.

\section{References}

1. Taylor, D. Physical activity is medicine for older adults. Postgrad. Med. J. 2014, 90, 26-32. [CrossRef]

2. Brach, J.S.; Vanswearingen, J.M. Interventions to Improve Walking in Older Adults. Curr. Transl. Geriatr. Exp. Gerontol. Rep. 2013, 2. [CrossRef]

3. Burton, E.; Mitchell, L. Inclusive Urban Design—Streets for Life; Elsevier: Oxford, UK, 2006; ISBN 978-0750664585.

4. Carstens, D.Y. Site Planning and Design for the Elderly: Issues, Guidelines, and Alternatives; Wiley: Hoboken, NJ, USA, 1993; ISBN 978-0-471-28537-3.

5. Cinderby, S.; Cambridge, H.; Attuyer, K.; Bevan, M.; Croucher, K.; Gilroy, R.; Swallow, D. Co-designing Urban Living Solutions to Improve Older People's Mobility and Well-Being. J. Urban Health 2018, 95, 409-422. [CrossRef]

6. Daskalopoulou, C.; Stubbs, B.; Kralj, C.; Koukounari, A.; Prince, M.; Prina, A.M. Physical activity and healthy ageing: A systematic review and meta-analysis of longitudinal cohort studies. Ageing Res. Rev. 2017, 38, 6-17. [CrossRef] [PubMed]

7. Ewing, R.; Handy, S. Measuring the Unmeasurable: Urban Design Qualities Related to Walkability. J. Urban Des. 2019, 14, 65-84. [CrossRef]

8. Flores, R.; Caballer, A.; Alarcón, A. Evaluation of an Age-Friendly City and Its Effect on Life Satisfaction: A Two-Stage Study. Int. J. Environ. Res. Public Health 2019, 16, 5073. [CrossRef]

9. Forsyth, A. What is a walkable place? The walkability debate in urban design. Urban Des. Int. 2015, 20, 274-292. [CrossRef]

10. King, A.; King, D. Physical Activity for an Aging Population. Public Health Rev. 2010, 32, 401-426. [CrossRef]

11. Alves, F.; Ramalho, A. Principles for the implementation of a pedestrian plan in medium size cities. Rev. Urban Reg. Dev. Stud. 2011, 23, 21-47. [CrossRef]

12. Nuzir, F.; Dewancker, B. Redefining place for walking: A literature review and key-elements conception. Theor. Empir. Res. Urban Manag. 2016, 11, 59-76.

13. Alves, F.; Cruz, S.; Ribeiro, A.; Silva, A.B.; Martins, J.; Cunha, I. Walkability Index for Elderly Health: A Proposal. Sustainability 2020, 12, 7360. [CrossRef]

14. Fatima, K.; Moridpour, S.; De Gruyter, C.; Saghapour, T. Elderly Sustainable Mobility: Scientific Paper Review. Sustainability 2020, 12, 7319. [CrossRef]

15. Goodman, R.; Tolley, R. The Decline of Everyday Walking in the UK: Explanations and Policy Implications; Woodhead Publishing: Sawston, UK; Cambridge, UK, 2003.

16. WHO World Health Organization. WHO Guidelines on Physical Activity and Sedentary Behavior. Available online: https: //www.who.int/publications/i/item/9789240015128 (accessed on 4 February 2021).

17. Ministry of Health. Guidelines on Physical Activity for Older People (Aged 65 and Over). Available online: https://www. health.govt.nz/system/files/documents/publications/guidelines-on-physical-activity-older-people-jan13-v3.pdf (accessed on 4 February 2021).

18. Rütten, A.; Pfeifer, K. Nationale Empfehlungen für Bewegung und Bewegungsförderung 2016. Available online: https://www. bundesgesundheitsministerium.de/service/begriffe-von-a-z/b/bewegungsempfehlungen.html\#: \{\}:text=Mit $\% 20 \mathrm{den} \% 20 \% 2$ 2Nationalen $\% 20$ Empfehlungen $\% 20 \mathrm{f} \% \mathrm{C3} \% \mathrm{BCr}$, unterschiedlichen $\% 20$ Lebenswelten $\% 20 \mathrm{gef} \% \mathrm{C} 3 \% \mathrm{~B} 6 \mathrm{rdert} \% 20 \mathrm{werden} \% 20 \mathrm{kann}$ (accessed on 4 February 2021).

19. Department of Health and Social Care. UK Chief Medical Officers' Physical Activity Guidelines. Available online: https: //www.gov.uk/government/publications/physical-activity-guidelines-uk-chief-medical-officers-report (accessed on 9 February 2021).

20. Notthoff, N.; Carstensen, L.L. Promoting walking in older adults: Perceived neighborhood walkability influences the effectiveness of motivational messages. J. Health Psychol. 2017, 22, 834-843. [CrossRef]

21. Draeger, W.; Klöckner, D. Ältere Menschen zu Fuß und mit dem Fahrrad. In Mobilität Älterer Menschen; Flade, A., Limbourg, M., Schlag, B., Eds.; Springer Fachmedien: Wiesbaden, Germany, 2001; pp. 41-67. ISBN 978-3-8100-3124-2. 
22. Gorrini, A.; Bandini, S. Elderly walkability index through GIS: Towards advanced aI-based simulation models. In Proceedings of the 17th International Conference of the Italian Association for Artificial Intelligence, Trento, Italy, 20-23 November 2018; pp. 67-82.

23. Schlag, B.; Beckmann, K.L. Demografische Entwicklung und zukünftige Mobilität. In Mobilität und Demografische Entwicklung; Schlag, B., Beckmann, K.L., Eds.; Eugen-Otto-Butz-Stiftung: Köln, Germany, 2013; Volume 7, pp. 21-40. ISBN 978-3-8249-1757-0.

24. Gorrini, A.; Crociani, L.; Vizzari, G.; Bandini, S. Observation results on pedestrian-vehicle interactions at non-signalized intersections towards simulation. Transp. Res. Part F Traffic Psychol. Behav. 2018, 59, 269-285. [CrossRef]

25. Gorrini, A.; Vizzari, G.; Bandini, S. Age and Group-driven Pedestrian Behavior: From Observations to Simulations. Collect. Dyn. 2016, 1, 1-16. [CrossRef]

26. Strohmeier, F. Barriers and their Influence on the Mobility Behavior of Elder Pedestrians in Urban Areas: Challenges and Best Practice for Walkability in the City of Vienna. Transp. Res. Procedia 2016, 14, 1134-1143. [CrossRef]

27. Garrard, J. Senior Victorians and Walking: Obstacles and Opportunities, Final Report. Available online: https://www. victoriawalks.org.au/Assets/Files/FINALSeniorsFullReport.pdf (accessed on 10 February 2021).

28. Zeng, F.; Schen, Z. Study on the Impact of Historic District Built Environment and its Influence on Resident's Walking Trips: A Case Study of Zhangzhou Ancient City's Historic District. Int. J. Environ. Res. Public Health 2020, 17, 4367. [CrossRef] [PubMed]

29. Papageorgiou, G.; Prodromou, M.; Christou, G.; Maimaris, A. Exploring the potential for developing a smart pedestrian navigation system for the Elderly market. In Proceedings of the 6th International Conference on Information Management (ICIM), London, UK, 27-29 March 2020; pp. 194-199.

30. Bass, B.J.; Livingston, M. Automotive retrofits in historic city centers and their potential effects on their walkability: A comparison of San Luis Obispo, CA, USA and Bath, England, UK. J. Urban Des. 2019, 24, 290-304. [CrossRef]

31. Balsas, C.J.L. City Centre Revitalization in Portugal: A Study of Lisbon and Porto. J. Urban Des. 2007, 12, 231-259. [CrossRef]

32. Campisi, T.; Canale, A.; Tesoriere, G. The development of walkability in the historic center of Enna: The case of the Saint Tommaso neighborhood. Eur. Transp. 2019, 73, e4.

33. American Heart Association. Know Your Target Heart Rates for Exercise, Losing Weight and Health. 2015. Available online: https:/ / www.heart.org/en/healthy-living/fitness/fitness-basics/target-heart-rates (accessed on 15 February 2021).

34. Mazuroski, A. Mobilidade Pedonal Urbana-Contribuições Para o Planeamento e Auditoria do Espaço Público na Mobilidade de Idosos. Master's Thesis, School of Science and Technology, Universidade Nova de Lisboa, Lisbon, Portugal, 2018.

35. Menor-Campos, A.; Pérez-Gálvez, J.C.; Hidalgo-Fernández, A.; López-Guzmán, T. Foreign tourists in world heritage sites: A motivation-based segmentation. Sustainability 2020, 12, 3263. [CrossRef]

36. Ribaudo, G.; Figini, P. The Puzzle of Tourism Demand at Destinations Hosting UNESCO World Heritage Sites: An Analysis of Tourism Flows for Italy. J. Travel Res. 2016, 56, 521-542. [CrossRef]

37. Mariani, M.M.; Guizzardi, A. Does Designation as a UNESCO World Heritage Site Influence Tourist Evaluation of a Local Designation? J. Travel Res. 2019, 59, 22-36. [CrossRef]

38. Adie, B.A. Franchising our heritage: The UNESCO World Heritage brand. Tour. Manag. Perspect. 2017, 24, 48-53. [CrossRef]

39. García, M.; Calle-Vaquero, M.; Yubero, C. Cultural Heritage and Urban Tourism: Historic City Centers under Pressure. Sustainability 2017, 9, 1346. [CrossRef]

40. Ramires, A.; Brandao, F.; Sousa, A.C. Motivation-based cluster analysis of international tourists visiting a World Heritage City: The case of Porto, Portugal. J. Destin. Mark. Manag. 2018, 8, 49-60. [CrossRef]

41. UrbiStat, S.R.L. Mappe, Analisi e Statistiche Sulla Popolazione Residente. Available online: https://ugeo.urbistat.com/ AdminStat/en/pt/demografia/eta/porto/20320039 (accessed on 26 January 2021).

42. City Population. Portugal: Regionen und Städte. Available online: https://www.citypopulation.de/de/portugal/cities/ (accessed on 26 January 2021).

43. UNESCO World Heritage Centre 1992-2021. Historic Center of Oporto, Luiz I Bridge and Monastery of Serra do Pilar. Available online: https:/ / whc.unesco.org/en/list/755 (accessed on 22 January 2021).

44. Municipality of Porto. Porto Reference Site for Healthy Ageing in the European Union. Available online: https://www.porto.pt/ en/news/porto_is_a_reference_site_for_healthy_ageing_in_the_european_union (accessed on 22 March 2021).

45. Mobi Age Promotion of Urban Mobility for Aged Populations. Available online: https://mobiage.dec.uc.pt/project/ (accessed on 14 January 2021).

46. Geofabrik GmbH. Portugal. Available online: https://download.geofabrik.de/europe/portugal.html (accessed on 2 November 2020).

47. Karndacharuk, A.; Wilson, D.J.; Dunn, R. A Review of the Evolution of Shared (Street) Space Concepts in Urban Environments. Transp. Rev. 2014, 34, 190-220. [CrossRef]

48. Karndacharuk, A.; Wilson, D.J.; Dunn, R.C.M. Analysis of Pedestrian Performance in Shared-Space Environments. Transp. Res. Rec. 2013, 1, 1-11. [CrossRef]

49. Ruiz-Apilánez, B.; Karimi, K.; García-Camacha, I.; Martín, R. Shared space streets: Design, user perception and performance. Urban Des. Int. 2017, 22, 267-284. [CrossRef]

50. Havik, E.; Melis-Dankers, B.J.M.; Steyvers, F.J.J.M.; Kooijman, A. Accessibility of Shared Space for visually impaired persons: An inventory in the Netherlands. Br. J. Vis. Impair. 2012, 30, 132-148. [CrossRef] 